\title{
Reflecting on the Origins of Fiberoptic Communication
}

"Imagine what the keen minds of our entertainment industry could do if they realized they had a hundred million channels into which they could funnel new and undreamed varieties of trash," wrote Isaac Asimov in 1962. The first working laser had been demonstrated just two years earlier and Asimov was contemplating what the new optical technology might mean for communications. "Maybe we should stop right now," he quipped.

No chance. The laser had inflamed the long-thwarted lust for optical communications systems. Within a decade, researchers at Bell Telephone Laboratories, Corning Glass, and elsewhere had invented the kinds of solid state lasers and photodetectors and glass fibers needed to build workable optical communications systems. In 1976, the first experimental optical fiber links were going on-line in offices. Since then, the frenetic wiring of the world with high capacity optical fibers has even brought a portion of Asimov's nightmare to near reality. There could well be a day in the near future when viewers will be able to choose from 500 channels of trash.

But long before the laser was invented, optical communication had racked up a lineage. In the ancient world large torches and sunlight reflectors served as optical signals that could be seen for miles. Flags served similar purposes since ancient times. In the $1790 \mathrm{~s}$, an optical telegraph using movable arms atop towers was designed in France. In 1840, the Prussian General Joseph Jakob Baeyer suggested that the heliotrope-an instrument that focuses sunlight into a narrow beam that Karl Friedrich Gauss had invented twenty years earlier for making land measurements-could serve well for transmitting messages. British and American military forces used a variation on that theme, called a heliograph, as an alternative to the electric telegraph.

The inventor of the telephone himself, Alexander Graham Bell, filed a patent in August of 1880, for a "photophone," which he demonstrated between a couple of rooftops along 14th Street in Washington, DC. A human voice caused a thin mirror to vibrate. A beam of sunlight reflecting from that mirror onto a selenium pickup altered the pickup's resistance in accordance with the changing light. This, in turn, modulated the amount of current going into a receiver. The result: a voice transmitted by light.

The telephone changed the world and the photophone did not because the photophone had a fatal flaw. A passing cloud could interrupt an act of communication and bad weather muted the gadget altogether. Nothing short of enclosing the beam of light could solve this problem.

An initial move in that direction occurred in 1854 when John Tyndall demonstrated to a gathering of the Royal Society how a bending stream of water could effectively trap light inside of it. He shined a beam of light through a glass wall of a water-filled tank and on through a tube fitted into the opposite wall of the tank. The light emerged as a white disk. But when Tyndall opened a stopcock on the tube so that the water could spout out of its end, something else happened. In his words, "the light upon reaching the limiting surface of air and water was totally reflected and seemed to be washed downward by the descending liquid, the latter being thereby caused to present a beautiful illuminated appearance."

This kind of total internal reflection, the very phenomenon that is the heart and soul of modern optical fibers, initially inspired ideas in building design more readily than in communication technology. In 1881, the year after Bell received his photophone patent, William Wheeler, an engineer in Concord, Massachusetts, applied for a patent for a system of hollow pipes with reflective interiors to distribute light from a central source throughout a building. His timing could have been better. The advent of incandescent lighting, in which light is produced locally using electricity, stranded Wheeler's idea into the category of things easily forgotten.

By 1930, several inventors in Britain and the United States helped to connect the transmission of light to glass fibers. Their patents, which involved solid glass or quartz fibers, had to do with transmitting images, not voices. One early application of the idea was to use flexible fibers for internal medical observations a la gastroscopy.

In 1934, Norman French, an engineer at the American Telephone and Telegraph Corporation, saw the relevance of such fibers to communications. He proposed that a network of "light cables" could carry voice traffic. These cables, French conjectured, could be made of "a solid rod of glass or quartz, or a similar material, which has a low absorption coefficient for the wavelengths to be transmitted." The problem was that nobody could make a "light cable" in which light could travel the length of a person, let alone the miles that would be necessary for a viable communications network.

Even in the 1950s, the prognosis was not looking good. Two internal reports at Bell Telephone Laboratories in 1945 and 1951, respectively, came up with pessimistic outlooks. The materials for guiding light were inadequate and the light sources available were not of the sort that behaved well when confined. The prescient author of the earlier report, W.A. Tyrell, even called for coherent light sources-lasers- -13 years before Charles Townes and Arthur Schawlow published the theoretical paper that led by 1960 to the creation of the first working laser.

The invention of the laser renewed interest around the world in optical communication. Just as before, bad weather made air a bad medium even for laser-based signals. In the mid-1960s, Wheeler's notion of hollow reflective pipes was revived, this time for communications applications instead of illuminating buildings. Researchers at Bell Telephone Laboratories built one version in which the pipes were filled with gas and then locally heated to create a lensing effect that refocuses the light along the pipe's length.

Another nemesis was lying in wait to again cut down Wheeler's vision. Elias Snitzer, who was then at American Optical, proposed in 1963 that the connection of lasers and optical fibers was the key to optical communications. He was right, of course, but his suggestion took a Panglossian act of optimism. Only one percent of the light going into a one meter length of the best made glass fibers at the time would emerge. Another meter's worth, and only one percent of one percent of the original input emerged. After a kilometer, it was profound darkness.

Grim as that seemed, two engineers at Standard Telecommunications Laboratories saw signs of hope. In an uplifting 1966 article they argued that the losses of 
light traveling in glass fibers were due largely to impurities in the glass and not to some fundamental limitation. Get enough of the impurities out, they predicted, and they would have the right stuff for optical fibers. Four years later, a group of glass researchers at Corning Glass confirmed the prediction by making the first glass fibers with sufficiently low light loss. By this time, solid state scientists also had made headway in the kinds of lasers and detectors that would have to be on the ends of optical fibers. A quarter of a century later, optical commu- nications has become a society-changing technology. With them, information superhighways are paved.

IVAN AMATO

For Further Reading: Sami Faltas, "The Invention of Fibre-Optic Communications," History and Technology 5 (1988) pp. 31-49; R. Kompfer, "Optics at Bell Laboratories-Optical Communications," Applied Optics 11 (November, 1972) pp. 2412-2425; Tingye Li, "Advances in Optical Fiber Communications: An Historical Perspective," IEEE Journal on Selected
Areas in Communications SAC-1 (April, 1983) pp. 356-372; J.B. MacChesney, "The Materials Development of Optical Fibers: A Case History," Journal of Materials Education 11 (1989) pp. 325-356; Ira Magaziner and Mark Patinkin, The Silent War: Inside the Global Business Battles Shaping America's Future (see chapter on Corning Glass), Vintage Books (New York, 1989); "A Revolution of Light: The Invention of Low-Loss Optical Fiber," a pamphlet published by Corning Incorporated, Opto Electronics Group.

\section{Ion-Beam Modification of Optics to Autos Treated at IBMM'95}

The Ninth International Conference on Ion Beam Modification of Materials (IBMM'95), chaired by J.S. Williams of the Australian National University (ANU), was held at ANU in Canberra, Australia, from February 5-10, 1995. More than 300 participants attended the conference from 33 countries. Over 420 abstracts were accepted, and papers were delivered in either poster or oral sessions. The location of the conference contributed to a higher than normal participation from Asia. Scientists from 33 countries attended the conference, the highest participation coming from Japan, followed by the United States, Germany, and Australia. In addition to IBMM'95, six informal supporting workshops, addressing key ion beam and materials issues, were held at various locations both before and after the conference. The 30-50 participants attending these workshops had ample time for discussion. The workshops were enjoyable and extremely stimulating, scientifically.

IBMM'95 covered traditional topics of this conference series but highlighted areas of particular relevance to the Australian research effort and areas that were internationally topical. Major topic areas included basic ion interactions, low energy processes, defects in semiconductors, high fluence implantation and phase formation, applications in electronics and optoelectronics, ion-beam modification of nonsemiconductors, and novel ion-beam equipment and techniques.

The conference was organized into 15 oral sessions, including three plenary presentations covering areas of general interest; 22 specialist invited papers and 51 contributed oral presentations; and three poster sessions. Several scientific highlights covered a diverse spectrum of materials and ion-beam processing methods. These included both conventional and novel applications of ion beams such as optical displays and optoelectronics, motor vehicle and tooling parts, coatings tailored for desired properties, studies of fundamental defect properties, the production of novel (often buried) compounds, and the treatment of biomedical materials.

The study of nanocrystals produced by ion implantation in a range of host matrices (plenary paper by H.H. Andersen, Denmark), particularly for optoelectronics applications (as indicated in a paper by H.A. Atwater, Caltech), was one especially new and exciting development. Despite several decades of study, major progress was reported at the conference in understanding defect evolution in semiconductors and the role of defects in transient impurity diffusion. A complete oral session was devoted to this topic, led by an invited presentation from D.J. Eaglesham, AT\&T Bell Laboratories. The use of implantation to tune or isolate optical devices and in forming optically active centers and waveguides in semiconductors (S. Coffa, Catania), polymers, and oxide ceramics (A. Polman, Amsterdam) was a major focus of several presentations at the conference. The combined use of ion-beam methods and more conventional means of growing and modifying buried compounds and three-dimensionallayered structures featured prominently, the main progress excellently reviewed in the plenary paper of S. Mantl, Julich. The formation of hard coatings by ion-assisted deposition or direct implantation (D. McKenzie, Sydney and J.C. Barbour, Sandia) was also an area which showed much recent progress. Ion-beam techniques had also developed a pace, particularly those based on plasma immersion ion implantation or alternative techniques for large area surface treatment (such as papers by J. Conrad, Wisconsin and I.G. Brown, Berkeley). Finally, the use of ion beams for the direct treatment of cancerous tissue (K.M. Horn, Sandia) was also a particularly novel and interesting application of ion beams.

In addition to several industrial sponsors and the ANU, the Australian Materials Research Society and the International Union of Materials Research Societies (IUMRS) cosponsored the conference.

J.S. WILLIAMS 